\title{
Misdiagnosis of primary hepatic marginal zone $B$ cell lymphoma of mucosa- associated lymphoid tissue type, a case report
}

\author{
L. X. Li, S. T. Zhou, X. Ji, H. Ren, Y. L. Sun, J. B. Zhang, H. B. Wang ${ }^{*}$ and Z. W. Liu*
}

\begin{abstract}
Background: Extra-nodal marginal zone B cell lymphoma of mucosa-associated lymphoid tissue originating in the liver is less common.

Case presentation: We described the clinical presentation, immunohistochemistry, and immunophenotypes of this lymphoma, which was misdiagnosed with tiny hepatic carcinoma in a 44-year-old woman with hepatitis $C_{\text {; }}$ the patient underwent left lateral sectionectomy. The immunophenotype identified the most of the lymphoid cells as positive CD20, CD34, Ki67, CD3, CD4, CD79a, CD45RO, MUM-1, and CD5 and negative CD10, CD15, CD30, ACT, CK, $\mathrm{CRO}, \mathrm{DES}$, and HMB45. The diagnosis of primary hepatic mucosa-associated lymphoid tissue (MALT) was made by histology after surgery; the patient went through the excellent recovery with no chemotherapy and is disease free for 27 months.

Conclusions: Primary hepatic MALT is less common with incidental finding; local resection is beneficial due to its oncological indolence.

Keywords: Extra-nodal marginal zone B cell lymphoma of mucosa-associated lymphoid tissue, CD20, Misdiagnosis, Left lateral sectionectomy
\end{abstract}

\section{Background}

In 1983, Isaacson et al. first described four patients with primary low-grade hepatic B cell lymphoma of mucosaassociated lymphoid tissue as a distinct entity [1]; later, the lymphomas were sporadically reported and its prevalence is very low [2-4]. Jaffe documented that hepatic malignant lymphomas comprised less than $1 \%$ of all malignant lymphomas, while hepatic mucosa-associated lymphoid tissue (MALT) lymphomas are reported to occur in only $3 \%$ of cases of hepatic malignant lymphoma [5]. Due to the heterogeneous clinical presentations and no specific manifestations of MALT, this lymphoma was commonly misdiagnosed with liver cancer in the absence of biopsy [6, 7]. Herein, we first focused on a primary hepatic MALT-type lymphoma misdiagnosed as

\footnotetext{
* Correspondence: wangh302h@126.com; liuz302h@126.com

Center of Hepatobiliary Surgery and Liver Transplantation, 302 Hospital, 100

Xisihuang Middle Road, Fengtai District, Beijing 100039, China
}

tiny liver cancer in a patient with hepatitis $\mathrm{C}$ virus (HCV)-associated cirrhosis who underwent left lateral sectionectomy.

\section{Case presentation}

A 49-year-old female patient of Han Ethnicity presented with mild distention pain in the right hypochondrium; her disease history included hepatitis $\mathrm{C}$ for about 10 years, and at that time, liver functions test was performed, revealing aminotransferase lightly beyond the upper normal limit. On physical examination, laboratories were significant for positive HCV antibody, quantitative HCV RNA was $1.28 \times 10^{6} \mathrm{cope} / \mathrm{ml}$, gene subtype is $1 \mathrm{~b}$, and no regular treatment of $\mathrm{HCV}$ was recorded. Tumor biomarkers were unremarkable, including alpha fetoprotein, carbohydrate antigens, and carcinoembryonic antigen; autoimmune diseases test were negative, and thyroid immunoglobulin was within the normal 
range. Enhanced MRI demonstrated a T1 and T2 hyperintensity round mass of $1.8 \mathrm{~cm}$ in the segment 3 of the liver which was enhanced in the early phase, clinically indicating tiny hepatocellular carcinoma (Figs. 1 and 2). Esphagogastroendoscopic findings indicated nonatrophic gastritis with erosions, and it was negative for Helicobacter pylori antibody. Polyp in the rectum was detected with colon endoscope, and biopsy revealed the inflammatory hyperplasia. The relevant cytogenetic testing was not performed, liver biopsy was not used to determine the imaging due to potential needle metastasis, and no periphery lymphadenopathy and splenomegaly were detected. Based on the history of chronic hepatitis $\mathrm{C}$ infection and almost typical imaging character, the diagnosis of tiny liver cancer was made, and left lateral sectionectomy was performed. Later pathology determined the primary hepatic marginal zone B cell lymphoma of mucosa-associated lymphoid tissue type. Its immunohistochemistry findings were positive for CD20(+++), CD5(+), CD34(+), Ki67(30\%+), CD3(+), CD4(++), CD79a $(++), C D 45 R O(++), M U M-1(+++)$, and fewer $\mathrm{Kappa}(+)$ whereas they were negative for CD8(-), CD10(-), HBsAg(-), HBcAg(-), HCV(-), Hepa(-), GPC3(-), CD15(-), CD30, CD56(-), lambda(-), and CB2(-) (Figs. 3 and 4). The patient experienced an uneventful recovery course. According to Ann Arbor staging, it was staged as IE. Chemotherapy was not applied even with the informed consent. The patient received combination of interferon $\beta$ and ribavirin for 48 weeks, and $\mathrm{HCV}$ DNA test was negative. Later, positron emission

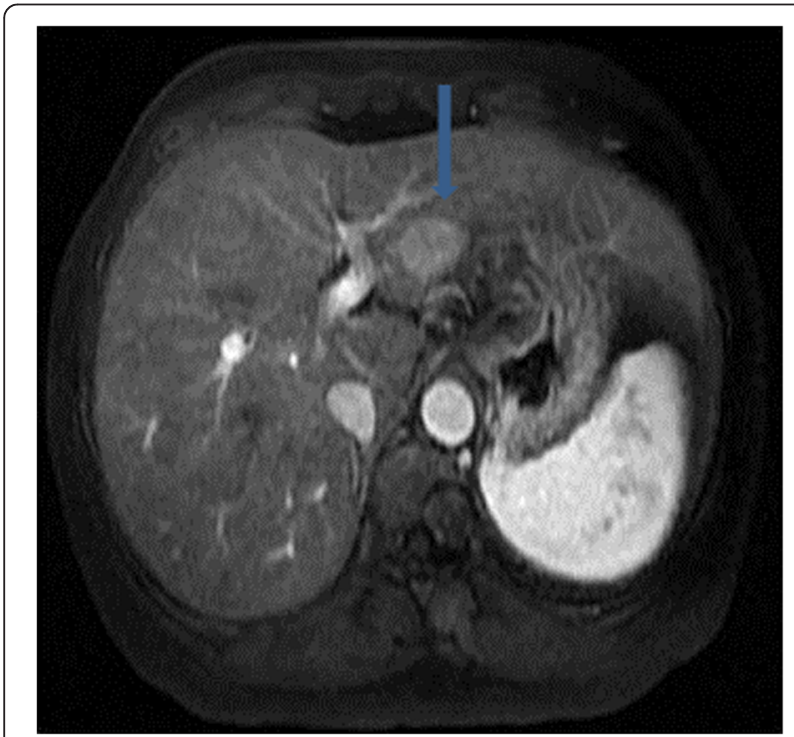

Fig. 1 MRI of the liver in a patient with chronic liver disease. Arterial phase extracellular Gd-chelate-enhanced MRI demonstrating a T1 and $\mathrm{T} 2$ hyperintense sphenoid lesion of $1.8 \mathrm{~cm}$ (arrow) in diameter in the $\mathrm{Sg} 3$ which is enhanced in the early phase

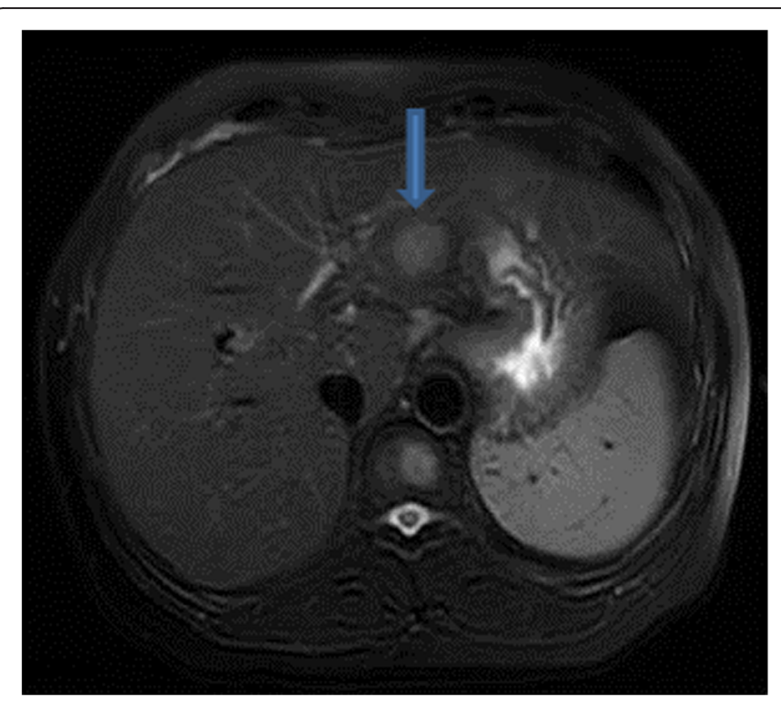

Fig. 2 Portal phase extracellular Gd-chelate-enhanced MRI demonstrating a T1 and T2 hypointense sphenoid lesion (arrow) in the $\mathrm{Sg} 3$ which is enhanced in the delayed phase, indicating a small hepatocellular carcinoma

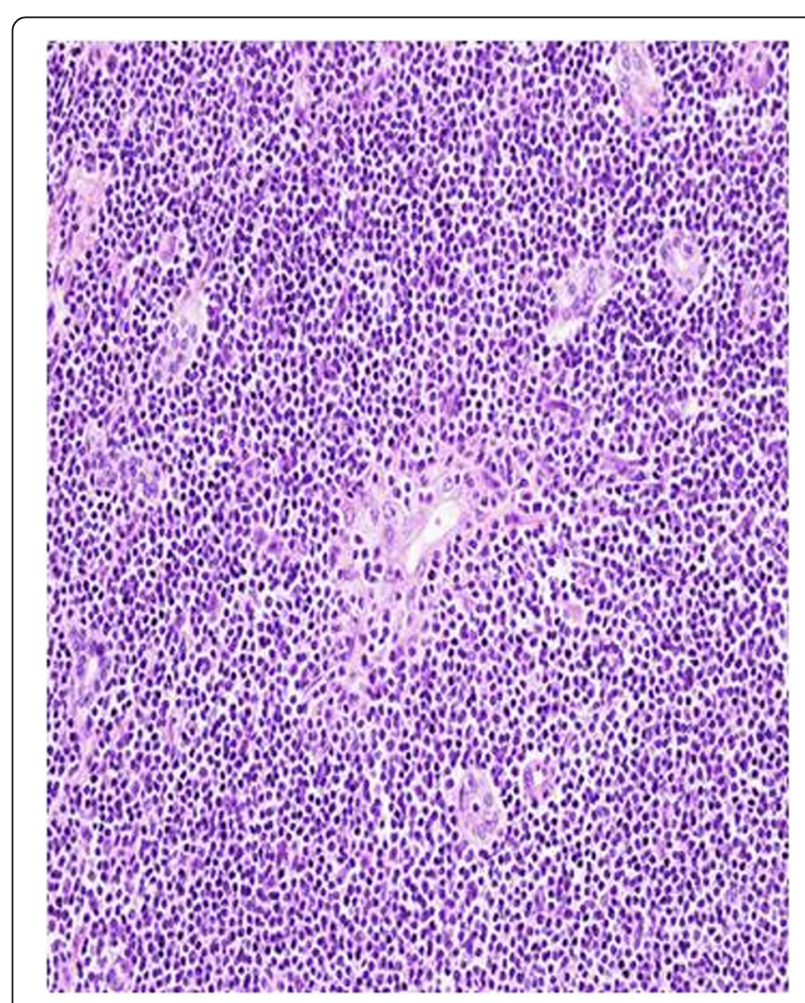

Fig. 3 Lymphoid cells infiltrated in the cirrhosis liver 


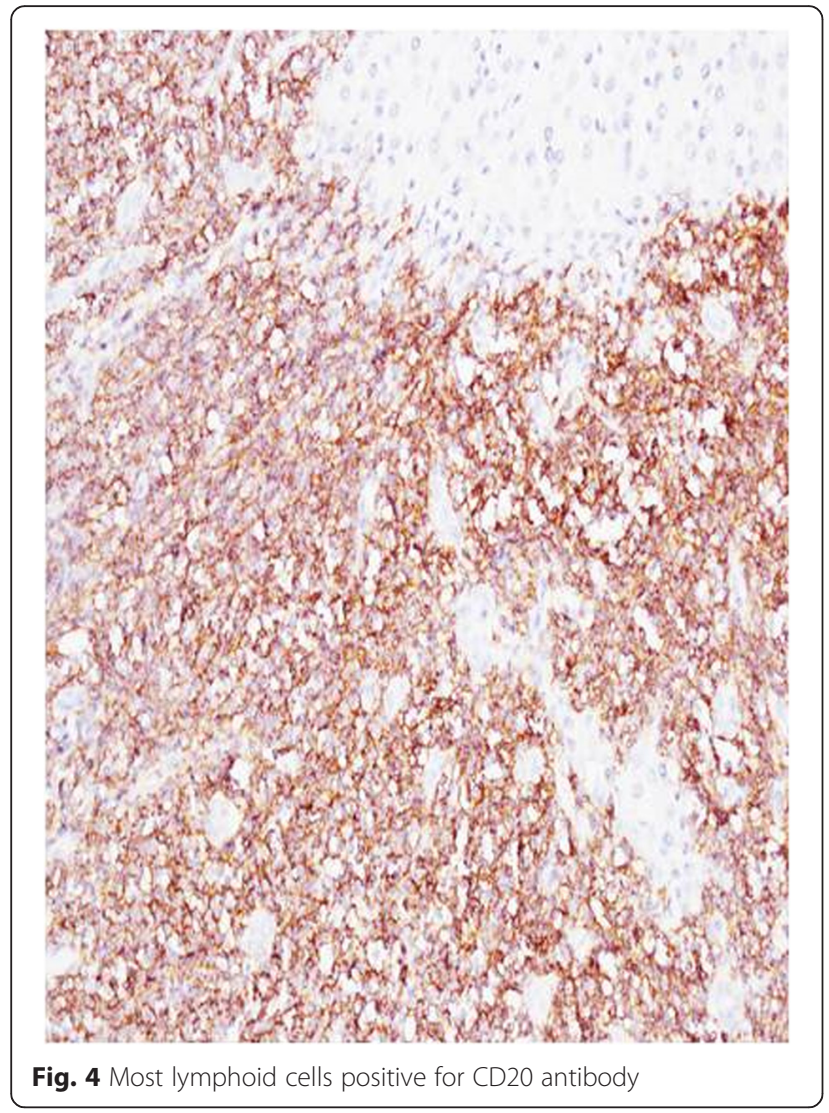

tomography-CT revealed no relapse, and Hashimoto thyroiditis was confirmed upon the elevation of thyroid immunoglobulin. At follow-up, the woman was doing well for over 2 years.

\section{Discussion}

The World Health Organization classified extra-nodal MALT lymphomas as low-grade ones characterized by their indolent, prolonged, localized, and clinical course and potential curability with local amendments [8]. The etiology of hepatic malignant lymphomas, especially MALT lymphomas, remains unknown. It was reported that Helicobacter pylori, hepatitis $\mathrm{C}$ virus, Epstein-Barr virus, and Borrelia burgdorferi were demonstrated in association with MALT lymphoma [9], and hepatitis C virus infection played a role in the occurrence of MALT reported by Ferri in 1993 [10]. Hashimoto's thyroiditis represents a background for the development of $94 \%$ of thyroid MALT lymphoma [11]. The molecular and cytogenetic data were very important, which not only contributed to a correct diagnosis but also shed light on the pathogenesis of this rare disease. The chromosomal translocations in MALT lymphoma was detected, and $t(11 ; 18)(q 21 ; q 21)$ is the most popular fusion signal in MALT lymphoma. B cell non-Hodgkin's lymphoma (B$\mathrm{NHL}$ ) is a well-documented complication of $\mathrm{HCV}$ infection. For our case with $\mathrm{HCV}$, the test for $H$. pylorus was negative, Hashimoto's thyroiditis followed MALT, and molecular and cytogenetic tests were unavailable due to money budget in China. We think chronic inflammation by HCV hepatitis may involve many types of cells including lymphocytes, and insidiously oncogenesis occurs.

No specific immuno-histochemical marker has yet been identified for MALT lymphoma. The presence of CD20(+) is highly suggestive of lymphoma, and so is CD5(+) too. CD5(+) allow us to differentiate chronic lymphocytic leukemia from small lymphocytic lymphoma or mantle cell lymphoma. Cyclin D1-positivity closely fits the characteristics of classical, typical lymphocytic leukemia [12]. So, the evaluation of a panel of immunostains is necessary for the assessment of the architecture of the lymphoid infiltrate, lineage assignment, and identification of an aberrant phenotype and for the exclusion of other lymphomas and facilitating differential diagnosis [13]. This report suggested that clinicians should be concerned about the possibility of hepatic MALT in HCV patients with a hepatic tumor as a differential diagnosis.

Generally, the prevalence of hepatic malignant lymphomas is extremely low, and it lacks specific clinical presentations and biomarkers. The imaging feature was similar to that of hepatocellular carcinoma (HCC), so it is commonly misjudged as an HCC [14] as well as, in our case, misdiagnosed as tiny liver cancer, although there were no findings to indicate a malignant lymphoma in systemic screening and preemptive resection would confer greatly on the patients. It is time to distinguish HCC from hepatic malignant lymphoma by following their criteria [15]. Contrast-enhanced image studies including angiography, dynamic CT, or Sonazoid-enhanced ultrasound might bring effective findings to distinguish them. Most of the time, biopsy works as the gold standard for the diagnosis of liver tumors including MALT if necessary, though it may spread tumors. To date, it needs warranting intensive investigations and greater case accumulations.

Ann Arbor staging depends on both the place where the malignant tissue is located and the systemic symptoms due to the lymphoma. Staging and classification guide the treatment options, and the treatment of lymphoma (gastric) continues to evolve. Disappearance of MALT-type lymphoma in patients infected with $\mathrm{HCV}$ has been reported after anti-viral treatment with interferon and ribavirin [16]. Lowgraded MALT is susceptible to resection while highgraded MALT carries poor prognosis due to early metastasis and low response to treatments. Our case was staged IE which indicated chemotherapy is not necessary, and no recurrence was detected for 27 months; long-lasting follow-up should be made to monitor if the patient is disease free. 
A written informed consent was obtained from the patient for hepatectomy and potential publication of this case report and any accompanying images.

\section{Conclusions}

Primary hepatic MALT is rare with incidental finding, and local treatment may be beneficial due to its oncological indolence.

\section{Abbreviations}

HCV: hepatitis C virus; MALT: mucosa-associated lymphoid tissue.

\section{Competing interests}

The authors declare that they have no competing interests.

\section{Authors' contributions}

$L X L$ wrote all drafts. STZ discussed the meaning of the draft and form it. HR and $\mathrm{XJ}$ collect all the references. YLS carried out the pathology. JBZ collected the clinical data. HBW performed the operation and discussed the draft. ZWL offered conception and finalized the draft. All authors read and approved the final manuscript.

Received: 23 November 2015 Accepted: 20 February 2016

Published online: 08 March 2016

\section{References}

1. Isaacson P, Wright DH. Malignant lymphoma of mucosa-associated lymphoid tissue. Cancer. 1983;52:1410-6.

2. Doi H, Horiike N, Hiraoka A, et al. Primary hepatic marginal zone B cell lymphoma of mucosa-associated lymphoid tissue type: case report and review of the literature. Int J Hematol. 2008:88:418-23.

3. Maes M, Depardieu C, Dargent J-L, et al. Primary low-grade B-cell lymphoma of MALT-type occurring in the liver: a study of two cases. J Hepatol. 1997;27:922-7.

4. Shin SY, Kim JS, Lim JK, Hahn JS, Yang WI, Suh CO. Longlasting remission of primary hepatic mucosa-associated lymphoid tissue (MALT) lymphoma achieved by radiotherapy alone. Korean J Intern Med. 2006;21(2):127-31.

5. Jaffe ES. Malignant lymphomas: pathology of hepatic involvement. Semin Liver Dis. 1987:7:257-68.

6. Zucca E, Conconi A, Pedrinis E, et al. Nongastric marginal zone B-cell lymphoma of mucosa associated lymphoid tissue. Blood. 2003;101:2489-95.

7. Kalpadakis C, Pangalis GA, Vassilakopoulos TP, et al. Clinical aspects of MALT lymphomas. Curr Hematol Malig Rep. 2014;9:262-72.

8. The JES. WHO classification of lymphomas: implications for clinical practice and translational research. Hematology. 2008;2009:523-31.

9. Cohen SM, Petryk M, Varma M, et al. Non-Hodgkin's lymphoma of mucosaassociated lymphoid tissue. Oncologist. 2006;11:1100-17.

10. Mattia AR, Ferry JA, Harris NL. Breast lymphoma. A B-cell spectrum including the low grade B-cell lymphoma of mucosa associated lymphoid tissue. Am J Surg Pathol. 1993;17(6):574-87.

11. Bacon CM, Du M-Q, Dogan A. Mucosa-associated lymphoid tissue (MALT) lymphoma: a practical guide for pathologists. J Clin Pathol. 2007;60:361-72.

12. Yatabe $Y$, Suzuki $R$, Tobinai $K$, Matsuno $Y$, Ichinohasama $R$, Okamoto $M$, et al. Significance of cyclin D1 overexpression for the diagnosis of mantle cell lymphoma: aclinicopathologic comparison of cyclin D1-positive MCL and cyclin D1-negative MCL-like B-cell lymphoma. Blood. 2000;95:2253-61.

13. Jaso J, Chen L, Li S, Lin P, Chen W, Miranda RN, et al. CD5-positive mucosaassociated lymphoid tissue (MALT) lymphoma: a clinicopathologic study of 14 cases. Hum Pathol. 2012;43:1436-43.

14. Papaxoinis G, Fountzilas G, Rontogianni D, et al. Low-grade mucosaassociated lymphoid tissue lymphoma: a retrospective analysis of 97 patients by the Hellenic Cooperative Oncology Group (HeCOG). Ann Oncol. 2008;9:780-6.

15. Sung Yong $\mathrm{O}$, Won Seog $\mathrm{K}$, Seok Jin $\mathrm{K}$, et al. Relapsed or refractory nongastric marginal zone B-cell lymphoma: multicenter retrospective analysis of 92 cases. Am J Hematol. 2009:84:826-9.

16. Hermine $\mathrm{O}$, Lefrère $F$, Bronowicki JP, Mariette $X$, Jondeau K, Eclache-Saudreau $V$, et al. Regression of splenic lymphoma with villous lymphocytes after treatment of hepatitis C virus infection. N Engl J Med. 2002;347(2):89-94.

\section{Submit your next manuscript to BioMed Central} and we will help you at every step:

- We accept pre-submission inquiries

- Our selector tool helps you to find the most relevant journal

- We provide round the clock customer support

- Convenient online submission

- Thorough peer review

- Inclusion in PubMed and all major indexing services

- Maximum visibility for your research

Submit your manuscript at www.biomedcentral.com/submit 